Article

\title{
Time Series Analysis of Online Public Opinions in Colleges and Universities and its Sustainability
}

\author{
Wei He ${ }^{1} \oplus$, Yuan Fang ${ }^{2, *}$, Reza Malekian ${ }^{3} \odot$ and Zhixiong $\mathrm{Li}^{4}$ \\ 1 School of Economics and Management, Minjiang University, Fuzhou 350108, China \\ 2 School of Mathematics and Statistics, Wuhan University, Wuhan 430072, China \\ 3 Department of Electrical, Electronic and Computer Engineering, University of Pretoria, \\ Pretoria 0002, South Africa \\ 4 School of Mechanical, Materials, Mechatronic and Biomedical Engineering, University of Wollongong, \\ Wollongong, NSW 2522, Australia \\ * Correspondence: 2011300710188@whu.edu.cn; Tel.: +86-18606990698; Fax: +591-83761175
}

Received: 4 May 2019; Accepted: 25 June 2019; Published: 27 June 2019

check for updates

\begin{abstract}
With the quick penetration of Internet applications, online media have become an important carrier of public opinions. The opinions and comments expressed by young college students-one of the most active netizen groups-on the Internet have turned out to be an essential part of the online public opinions in colleges and universities. However, the existing systems generally employ simple statistical methods to analyze the effect of online public opinions on the image and reputation development of colleges and universities without taking account of other factors, such as the hotness characteristics of online public opinions and semantic information. Therefore, on the basis of Public Opinion Hotness Index and time series-based trend analysis, as well as the topics extracted using the latent Dirichlet allocation (LDA) topic model, this study aims to improve the analysis performance on the online public opinions in colleges and universities using short-term trend prediction results. The experience and lessons learned from a real case may provide strong data support and feasible suggestions for colleges and universities in analyzing and guiding the online public opinions.
\end{abstract}

Keywords: online public opinions; public hotness sustainability; time series forecasting; LDA topic model

\section{Introduction}

With the rapid development of information networks, the Internet has become an essential part of our social life. The emergence of online media, such as news websites, forums, Weibo, and WeChat, has significantly improved the efficiency of information dissemination and opinion expression, which makes the Internet a popular carrier of social public opinions. Therefore, the academic community has conducted studies on the online public opinion analysis and defined it as "Online public opinion is the combination of political beliefs, attitudes, opinions and emotions expressed by the public on the Internet towards government's governance and the various phenomena and issues in the real society" [1]. On the one hand, as a platform for people to express opinions, online public opinion provides a realistic basis for government decision-making. It is also a positive force to promote social progress. On the other hand, it may cause panic or other harmful emotions and bring social risks due to false news dissemination [2]. Therefore, accurate analysis and reasonable response to online public opinion is crucial to promote sustainable social development, which means measuring a useful index of the opinions and controlling their dissemination in the social network in a healthy manner to reduce or prevent negative effects to the public. 
In the same way, as the subsystem of the social system, the colleges and universities continuously optimize the basis of stable operation to achieve sustainable development of the image and reputation of colleges and universities. The network public opinion of colleges and universities is the vane of various links in the university system. Young college students who have grown up from the Internet environment are used to expressing their opinions and emotions through the Internet. They are one of the most important groups in the network production of colleges and universities. When there is a problem in a certain part of the university system, it may lead to the infringement of the interests of college teachers and students or the risk of possible infringement. Students will actively express their opinions and demands as a communication manner to discuss with the university management department. Of course, the affirmative opinion on the operation of colleges and universities can help university administrators continue to implement reasonable management plans and, on this basis, continuously optimize the operation of the university system.

Moreover, college students are the mainstay of online public opinion production in colleges and universities. They not only express their opinions on the operation of the university system but also social public emergencies. Due to the lack of abilities to screen information, control emotions and carry out in-depth thinking, their comments made on public incidents/emergencies through the Internet are always massive, emotional, irrational, and uncontrollable. Therefore, they are often used as a target by people who are trying to disrupt the stability of colleges or universities. With the help of online public opinion, the implementation of offline behaviors that maliciously disrupt the order of colleges and universities will eventually lead to social chaos. Different from the positive influence of the network public opinion on the improvement and consolidation of the university system, the irrational network sensation of colleges and universities will bring great challenges to the smooth operation and sustainable development of the image and reputation of colleges and social systems. Accurate analysis and correct guidance of college network grievances can promptly clarify facts, resolve contradictions, and reduce the possibility of social chaos. It is of great significance to the stability of colleges and universities and sustainable development of their images and reputation. Simultaneously, unlike theoretical teaching in the classroom, the reasonable response to online public opinion is a kind of practical teaching, which helps students to acquire the knowledge, ability and values that correctly deal with the relationship between people and society, as well as economy and nature. This is an important part of sustainable education [3] and also is the background of this study.

In addition, according to previous research results in literature, the current management departments of colleges and universities have gradually paid more attention to the network public opinion of colleges and universities and begun to establish a special network public opinion analysis institution to study the countermeasures of network public opinion analysis in colleges and universities. Because it is still in the exploratory stage, college management departments still have many problems in the cognitive, control, and processing aspects of online public opinions [4]. For example, the analytical method that they use still relies on subjective experience judgment rather than lyric data analysis, and most of the coping styles are post-negative explanations or suppression of online opinions. These methods are not only difficult to accurately grasp lyric content but also easy to further stimulate contradictions and disrupt the normal operation of colleges and universities, and hence, hinder the sustainable development of the image and reputation of colleges and universities. This is the main reason why this paper explores more scientific and effective college public opinion analysis and response methods. Figure 1 illustrates how university network public opinion affects the sustainable development of the image and reputation of colleges and universities. 


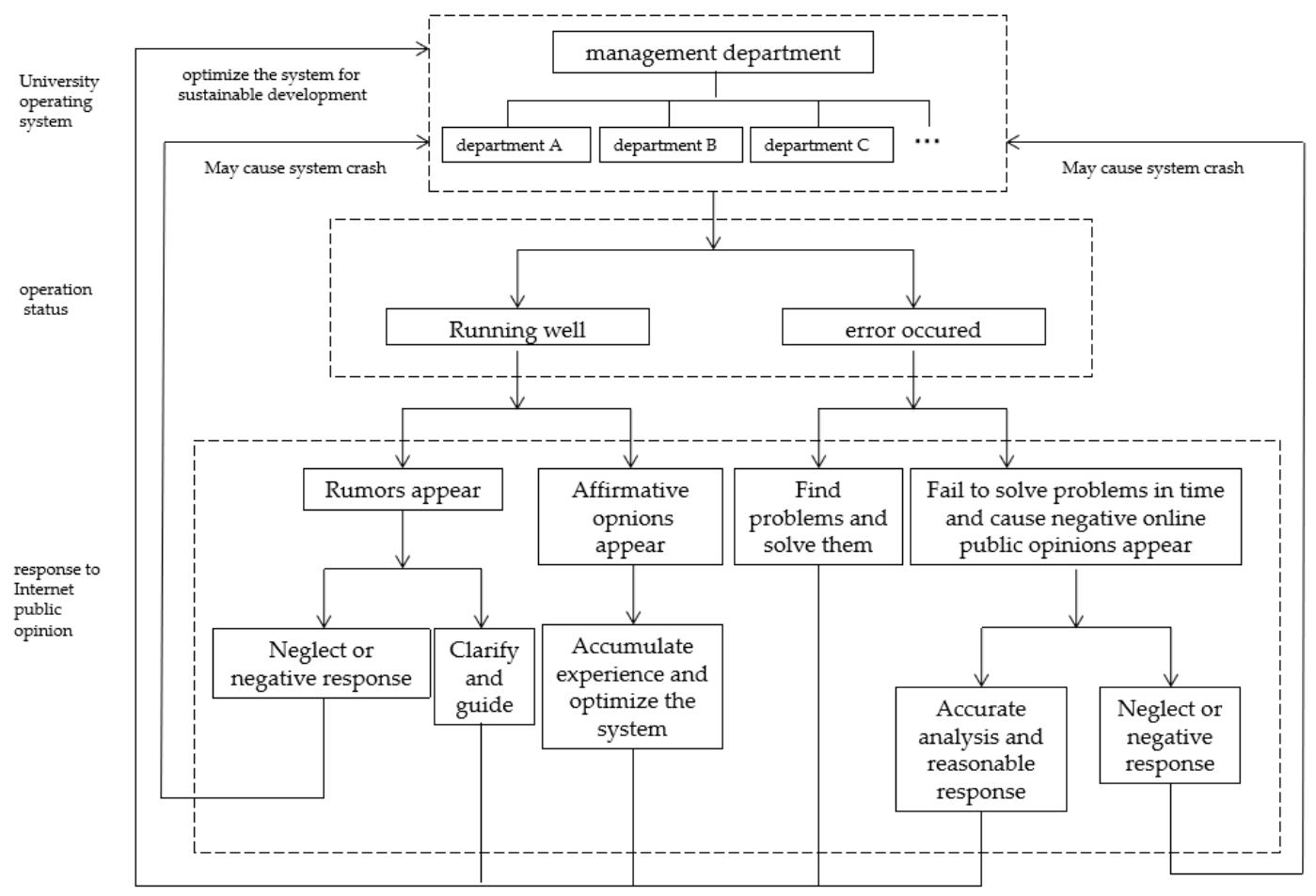

Figure 1. Flow chart of the effect of college network public opinion on the sustainable development of the image and reputation of colleges and universities.

The structure of the paper is organized as follows: Section 1 explains the social background and reasons for conducting this research. Section 2 reviews the related work, mainly on the connotation and characteristics of the network public opinion, the evolution mechanism, the monitoring and coping methods, and comparison of research methods. Sections 3-5 are the main contents of this study. Section 3 introduces four modules of the network public opinion analysis system based on time series, that is, the data acquisition module, time division module, trend analysis module, and opinion analysis module. The autoregressive integrated moving average (ARIMA) model for short-term prediction of network public opinion and the LDA topic extraction technology for public opinion analysis are also introduced. In Section 4, a case study of "University Banning Food Delivery Service from Campus" is carried out. Section 5 analyzes how colleges and universities achieve sustainable development in terms of image and reputation based on the analysis methods and case analysis results presented in this paper. The last section summarizes this research.

\section{Related Work}

With the booming development of the Internet, incidents stirring widespread online discussion-especially incidents taking place in colleges and universities-have been increasing year by year. In this regard, the academic community has paid considerable attention to the online public opinions in colleges and universities.

\subsection{Connotations and Characteristics of Online Public Opinions in Colleges and Universities}

The discussions over the connotations and characteristics of online public opinions in colleges and universities have served as the basis and starting point for the relevant research, but debates remain in the academics. From the perspective of the communication carrier, some argue that the online public opinions in colleges and universities refer to the opinions and comments that are communicated on the Internet and are related to the work in colleges and universities [5]. This argument stresses that the content of communication is closely bound up with the work of colleges and universities, whilst the carrier of communication is the Internet in the general sense. Others believe that the online 
public opinions in colleges and universities refer to the combination of opinions expressed by a certain number of college teachers and students on the campus network over a certain "publicly concerned" or "hot" issue [6]. College teachers and students are the main participants of communication, and the campus network is the carrier of communication. From the perspective of communication participants, two different theories- "students being the main participants of communication" and "teachers and students being the main participants of communication"-remain active in the academics. Still, most research papers regard young college students as the actual spreaders of online public opinions; precisely, they define the concept as "online public opinions of college students" [7].

Different scholars look at different aspects of the characteristics of online public opinions in colleges and universities, yet most of them put focus on the individualization and group polarization of communication participants, the richness and diversity of communicated content, the immediacy of and the interaction between communication carriers, the concealed and explicit forms of public opinions, and the emotional and irrational aspects of public opinions [8]. Up to today, the academic community has carried out systematic explorations on the basic concepts of online public opinions in colleges and universities, such as the connotations and characteristics, and laid a solid foundation for the follow-up studies on the response to and the control of online public opinions in colleges and universities.

\subsection{Formation and Evolution Mechanism of Online Public Opinions in Colleges and Universities}

Among discussions on the formation and evolution mechanism of online public opinions in colleges and universities, although there have been different arguments, the following stages can be summarized on the basis of previous research: (1) At the first stage, the occurrence of an incident catches the attention of communication participants who then initiate public discussions; (2) at the second stage, with the gradual convergence of opinions over the incident, online public opinions take shape; (3) at the third stage, different opinions interact and integrate with each other, and dominant opinions are gradually generated and strengthened; and (4) at the fourth stage, online opinions lead to offline actions, and the responses of the affected party will largely determine whether the public opinions will be further strengthened and expressed through real actions or be gradually calmed down and vanished [9]. Someone also argues that the emergence of public opinions over an incident results from the "agenda setting", the emergence of "opinion leaders" gives rise to influential opinions, the "amplification effect" of communication interactions contributes to the spread of opinions, and the increase of negative news leads to the development of "stereotype". Eventually, the "secondary development" leads to the spread of public opinions [10]. This argument provides a theoretical explanation for the evolution of online public opinion in colleges and universities, but its division of stages is similar to other studies. It can be seen that although such online public opinions spread freely and are difficult to control they exhibit certain laws of evolution.

\subsection{Monitoring and Coping of Online Public Opinions in Colleges and Universities}

The monitoring and coping of online public opinions in colleges and universities has been the focus of research in certain fields involving different disciplines. Such research is mainly concentrated in the field of ideological and political education. Some scholars believe that we must give full play to the role of counselors and student cadres as "opinion leaders" in order to strengthen mainstream thoughts. Some believe that we must rely on the ideological and political education department to set up a public opinion monitoring system in order to screen and filter the online public opinions in colleges and universities, or we must train online commentators to guide biased views [11]. Others argue that we must start from the establishment of relevant mechanisms, such as the online public opinion work leadership mechanism, response team mechanism, education guidance mechanism, intervention guidance mechanism, crisis management mechanism, and work feedback mechanism [12]. There are also studies on establishing a public opinion intervention mechanism from five aspects: Root 
cause collection and monitoring, analysis and judgment, security warning, public opinion guidance, and crisis management [13].

In conjunction with the journalism and communication theories, some scholars suggest to seize the commanding heights when attempting to guide the online public opinions in colleges and universities, such as: (1) Drawing attention through "agenda setting" and giving full play to the communication advantages of new media in responding to the public opinions, (2) cultivating online public opinion "gatekeepers" with professional skills and improving the media literacy of young college students in order to improve their ability to process complex public opinions, and (3) leveraging official media and campus media to optimize the public opinion guidance process according to the advantages of different media [14].

However, the early studies on the analysis of online public opinions in colleges and universities were generally normative research based on empiricism. With the rapid development of the Internet technologies and new media, the current patterns of online information dissemination and the thoughts and behaviors of young college students in spreading and acquiring information are exhibiting new characteristics in the new era, such as the emergence of "anti-spiral of silence" in the era of self-media. Therefore, relying on the past experience and the relevant theories to guide such online public opinions might not achieve good results in the new era. In this regard, over the past two years, the academic community has begun to study the characteristics, generation mechanism, and evolution laws of the online public opinions in colleges and universities by introducing rigorous and scientific modeling methods. For example, a study introduced the model from system dynamics and employed the Vensim PLE software to carry out simulation and eventually concluded that efforts must be made to improve the transparency of information disclosure in order to enhance the credibility of college/university, divert the focus of public opinions, and give full play to the role of media in order to improve response efficiency [15].

However, most of the existing systems for analyzing public opinions in colleges and universities fail to integrate big data mining technology [16]. They still use the traditional manual processing method at the stage of online data acquisition. Given the exponential growth of online information, this method could probably compromise the accuracy of results due to such defects as incomplete information acquisition and limited analysis dimensions. Therefore, applying big data mining technology to collect and analyze public opinions through online information has become the trend and focus of current researches.

Compared with the existing research results on college network public opinion, the innovations of this paper are as follows. Firstly, web crawler code for data mining is used in this study to analyze the university network public opinion. This method can avoid the problem of incomplete data capture caused by manual statistics. Secondly, the time series theory and the semantic information-based topic extraction method are employed to evaluate the hotness level and semantic information of public opinions. The mathematical model for trend prediction is more realistic and reliable than the previous subjective qualitative analysis. In addition, in this paper, we compare three common trend prediction models and find that the proposed prediction model for short-term trend is more effective. Thirdly, this paper expounds the important role of college network public opinion response to the sustainable development of the image and reputation of colleges and universities rather than just analyzing a particular college network sensation event, which provides a new perspective for research in related fields.

\section{Proposed Method}

\subsection{System Framework}

The time series-based system for analyzing online public opinions in colleges and universities mainly includes four modules: Data Acquisition Module, Stage Division Module, Trend Analysis Module, and Opinion Analysis Module. 
(1) Data Acquisition Module. As a new type of communication carrier, the Internet has provided great convenience and freedom for opinion dissemination and serves as a platform for college teachers and students with strong individual awareness and strong desire to express this. The unique immediacy and interactivity of the Internet allow netizens to influence each other, facilitate group polarization, and give rise to dominant public opinions. Therefore, in the Data Acquisition Module, we take public websites (such as Baidu Post Bar, college forums, and Sina Weibo, where the opinions of college teachers and students are concentrated) as the data sources to collect he necessary datasets.

The Data Acquisition Module involves two specific activities: (1) To collect data by making a web crawler or by applying existing web crawler tools [17] so as to analyze the evolution characteristics of netizens' topics through the text data acquired and (2) to determine the hotness level of public opinions through the number of articles posted, the number of comments, and the topic search index. For example, Baidu would release the Baidu Index [18] of a certain topic to show the hotness level of such topic during the period of public opinion evolution. According to the particularity of public opinions, when collecting the public opinion data, our system is capable of searching for the Baidu Index of the topic and taking it as a Public Opinion Hotness Index for trend analysis, after which the system will further crawl websites for relevant articles or comments to allow opinion mining.

(2) Stage Division Module. In the objective world, the emergence and development of any matter has its life cycle, and so is the evolution of public opinions. The process of dividing the life cycle of the evolution of public opinions is called "Stage Division". In the Crisis Life Cycle theory, Steven Fink [19] divides sudden public incidents/crises and the emergency management process into the prodromal stage, the acute stage, the chronic stage, and the resolution stage. On such a basis, this study divides the evolutionary process of online public opinions in colleges and universities into four stages: the prodromal, outbreak, fluctuating, and fading stages [20-22].

Based on the Public Opinion Hotness Index and the text data of opinions, the Stage Division Module divides the evolution process of public opinions into different stages through the following approach: (1) Select a point closest to the highest index value and with a slope greater than 1 as the boundary point between the prodromal stage and the outbreak stage, (2) select the first minimum point behind the highest point as the boundary point between the outbreak stage and the fluctuating stage, and (3) select a point with the smallest slope behind the outbreak stage as the boundary point between the fluctuating stage and the fading stage.

(3) Trend Analysis Module. After the stages have been divided, the time series concept is introduced in the Trend Analysis Module. "Time series is a sequence of different values of a certain indicator at different times, arranged in chronological order" [23]. It is often used for quantitative forecasting in the research. The topics and hotness level of online public opinions will change and show different characteristics with the lapse of time, exhibiting certain evolution laws. Therefore, the analysis system proposed in this paper will analyze the development trends of public opinions based on the hotness index. This module involves the test of the hotness index series, the selection of time series forecasting model, and the application of such model in the short-term trend forecasting of public opinions.

(4) Opinion Analysis Module. The Opinion Analysis Module extracts public opinion topics of different stages based on the text data of Weibo articles and comments posted by netizens for the purpose of exploring the evolution characteristics of netizens' public opinions and grasping the direction of public opinions. In practice, this module mainly involves the topic extraction, keyword extraction and word cloud creation.

Figure 2 shows the framework of the time series-based system for analyzing the online public opinions in colleges and universities. 


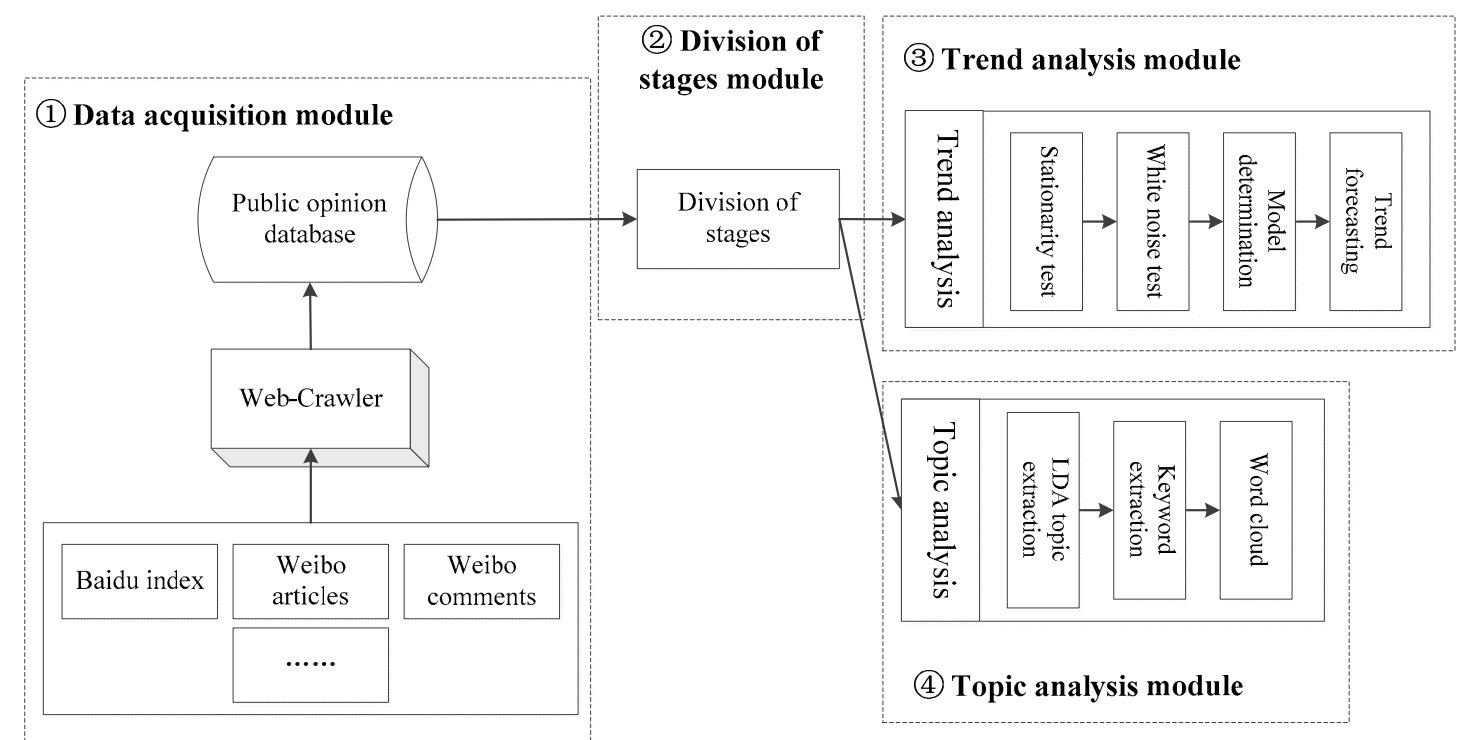

Figure 2. Framework of the time series-based system for analyzing online public opinions in colleges and universities.

\subsection{Key Technologies}

\subsubsection{Trend Analysis}

As mentioned above, the Trend Analysis Module uses the time series algorithm to forecast the evolution of an incident stirring online discussions. It takes Baidu Index as the Public Opinion Hotness Index and selects the ARIMA model [24] to carry out short-term trend forecasting of public opinions so as to provide data support for forecasting the trend of online public opinions in colleges and universities.

The ARIMA modeling process involves stationarity test, white noise test, model order determination, and trend forecasting.

(1) Stationarity test. The ARIMA model requires that the data to be analyzed must be a stationary series, and employs Unit Root Test (ADF) to examine whether the subject series is a stationary series. If it is a non-stationary sequence, the differencing operation is used to make the time series stationary.

(2) White noise test. The white noise series refers to the stationary series without any correlation between the values and having no extractable information, which makes analysis pointless. If a series is found to be non-white noise series, model order determination can be proceeded, or else the analysis should be terminated.

(3) Model order determination. Based on the autocorrelation plot, partial autocorrelation plot, and the Bayesian information criterion (BIC), the optimal parameters are determined for the ARIMA $(p, d, q)$ model.

(4) Trend forecasting. Use the optimal model to carry out short-term forecasting of the Public Opinion Hotness Index. Figure 3 shows the ARIMA modeling flow chart. 


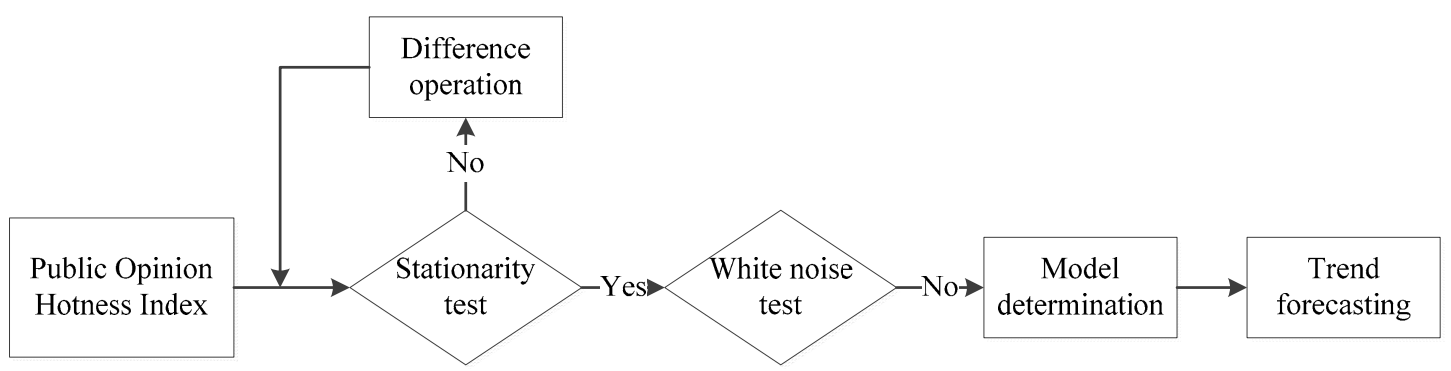

Figure 3. Autoregressive integrated moving average (ARIMA) modeling flow chart.

\subsubsection{Topic Analysis}

The Topic Analysis Module is mainly used to extract topics and keywords from the text data and to visually display the tendency of topics in a graphical form. Based on the Weibo articles and comments collected, the system employs LDA topic model [25] to extract public opinion topics and the keywords under each topic and then analyzes the changes in topics at different stages through the word cloud. The core idea of the LDA topic model is that each word in an article is obtained through a process of "choosing a topic with a certain probability and selecting a word with a certain probability from this topic". A graph model of LDA is shown in Figure 4, where $M$ denotes the number of documents, $N$ denotes the number of words in document $m$, and $\alpha$ and $\beta$ are the priors on the per-document topic probability distribution $\theta$ and the per-topic word probability distribution $\psi$, respectively. The processes represented in the graph model are described as follows:

(1) $\quad \alpha \rightarrow \theta_{m} \rightarrow Z_{m, n}$. This process involves the following steps: Extracting topics from the topic distribution $\theta$ and sampling the probability of each keyword from the topics;

(2) $\quad \beta \rightarrow \psi_{k} \rightarrow W_{m, n}$. This process involves the following steps: Selecting keywords to generate probability distribution $\psi$ and selecting the corresponding keyword by combining this distribution with the topic.

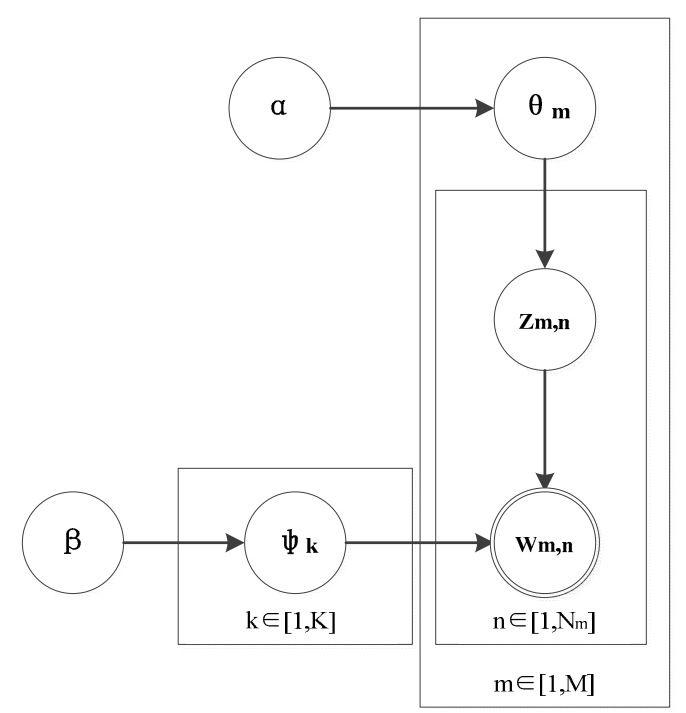

Figure 4. Latent Dirichlet allocation (LDA) graph model.

By leveraging the LDA topic model, we can extract various topics from the text data and the most likely keywords under each topic. Therefore, the Topic Analysis Module extracts prevailing topics of different stages and the keywords under each topic and visually displays the changes in topics from stage to stage through the word clouds. 


\section{Case Study}

In order to evaluate the performance of the above-mentioned system model, a case study on the incident of "University Banning Food Delivery Service from Campus" was carried out. Based on the system framework, as shown in Figure 2, this paper uses the actual data to analyze the hotness trend and topics of the online public opinions in colleges and universities and elaborates on the analysis process and results of each step.

\subsection{Data Acquisition and Stage Division}

Baidu and Sina Weibo are two important platforms where college students express their opinions. Therefore, these two platforms were used as the source of empirical data for this case study. In the Data Acquisition Module, we used Python to create the web crawler and took "a specific university" as the keyword to collect the daily Baidu Search Index in the period from 20 October 2018 to 8 December 2018 as the Hotness Index of this incident. We further used the web crawler to collect 118,973 original articles and 9611 comments found using the keyword of "University Banning Food Delivery Service from Campus" on Sina Weibo during this period and took them as the text data for the topic analysis of this incident.

In the Stage Division Module, based on the Public Opinion Hotness Index requirements, the development process of this incident was divided into four stages, as shown in Figure 5.

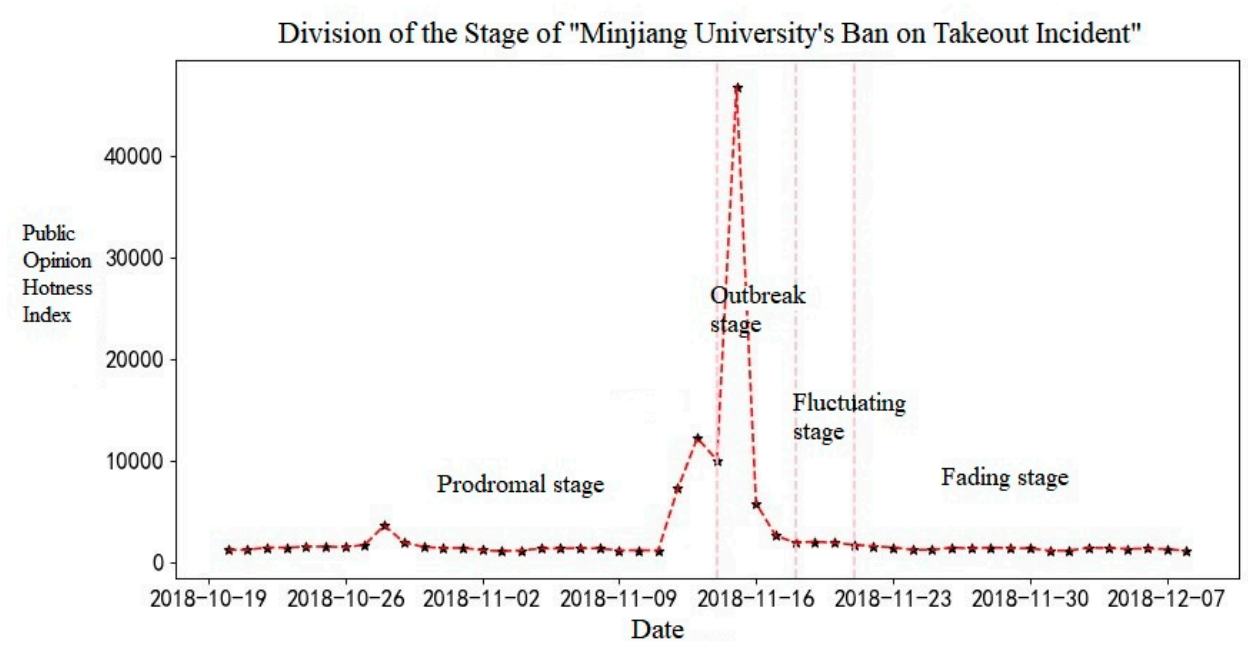

Figure 5. Stage division for the incident of University Banning Food Delivery Service from Campus.

Figure 5 shows that the Hotness Index of the incident of "University Banning Food Delivery Service from Campus" began to soar from 12 November 2018 and peaked on 15 November 2018. The university announced a ban on food delivery service on campus on 11 November 2018. According to Figure 5, this ban quickly stirred widespread public attention upon release and came to the outbreak stage in a very short period of time. The Public Opinion Hotness Index reached a peak on 15 November 2018. However, given the particularity of this incident, its hotness level slumped quickly and stabilized within a relatively short period of time. To conclude, this incident did have four stages: The prodromal, outbreak, fluctuating, and fading stages.

\subsection{Trend Analysis}

With regard to the Public Opinion Hotness Index of the incident of "University Banning Food Delivery Service from Campus", we introduced the Trend Analysis Module [26] and applied the time series analysis to set up a suitable ARIMA model to forecast the short-term trend of this incident. Based on the Public Opinion Hotness Index in Figure 5, it can be seen that the development process of 
this incident shows a significant increasing-decreasing trend, which is a non-stationary series. The following stationarity test and white noise test were performed on this series:

(1) Stationarity Test. This paper uses the augmented Dickey-Fuller (ADF) test to examine the stationarity of original series. The results are shown in Table 1.

Table 1. Augmented Dickey-Fuller (ADF) test results.

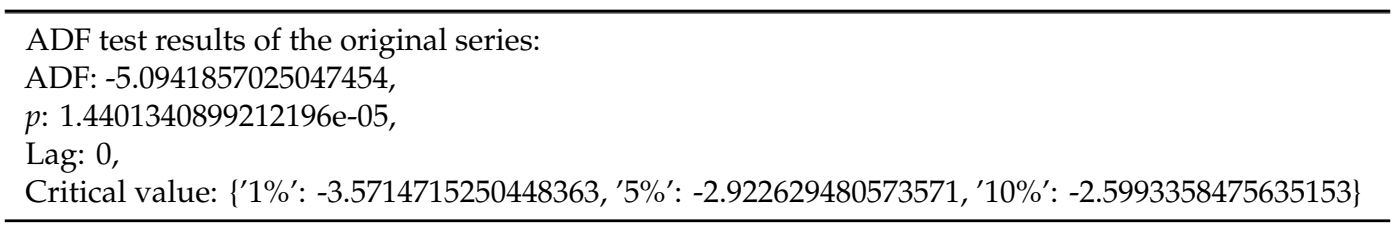

As shown in Table 1, the ADF test results show that $p=1.44 \times 10^{-5}$, which is far less than 0.05 . This implies that the original series of the Public Opinion Hotness Index pertains to a stationary series. Therefore, the ARIMA model can be used without the need of differential processing.

(2) White Noise Test. Table 2 shows the results of a white noise test for the Public Opinion Hotness Index. It can be seen that $p=0.03589$, which is less than 0.05 . This implies that this series is a non-white noise series.

Table 2. White noise test results.

\begin{tabular}{l} 
White noise test results of the differential series: \\
Statistics: 4.40227719 \\
$p: 0.03589098$ \\
\hline
\end{tabular}

(3) Model Order Determination. With regard to the Public Opinion Hotness Index, $p$ and $q$ are determined based on the autocorrelation plot, the partial autocorrelation plot, and the Bayesian information criterion (BIC). Figure 6 and Table 3 show the results.

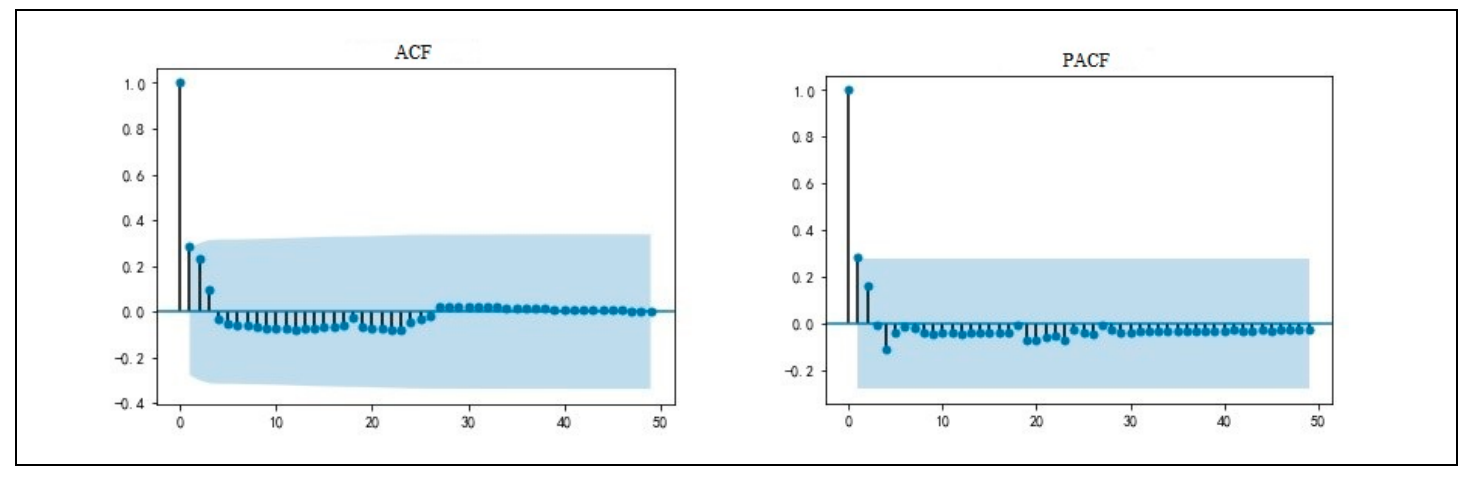

Figure 6. Autocorrelation and partial autocorrelation analysis.

Table 3. Bayesian information criterion (BIC) matrix of ARMA $(p, q)$ models.

\begin{tabular}{ccccccc}
\hline $\boldsymbol{q}$ & $\boldsymbol{p}$ & $\mathbf{0}$ & $\mathbf{1}$ & $\mathbf{2}$ & $\mathbf{3}$ & $\mathbf{4}$ \\
\hline 0 & 1029.4447 & 1030.2439 & 1032.08999 & 1035.1663 & 1039.0776 & 1042.9738 \\
1 & 1029.09748 & 1032.12048 & 1035.39698 & & & \\
2 & 1031.7206 & 1035.6322 & 1039.0754 & & & \\
3 & 1035.6317 & 1039.4775 & 1042.9831 & 1046.8647 & & \\
4 & 1039.0312 & & 1042.8911 & & & \\
\hline
\end{tabular}

According to the autocorrelation and partial autocorrelation plots in Figure 6 and the BIC matrix in Table 3, when the $p$ and $q$ are 0 and 1 respectively, the BIC value is the smallest in the model, meaning 
that the forecasting model is optimal in such a case. Therefore, the ARMA $(0,1)$ model was selected to forecast the short-term trend of the Public Opinion Hotness Index Series of the said incident.

(4) Trend Forecasting. By employing the $\operatorname{ARIMA}(0,1)$ model, we forecasted the development trend of the Public Opinion Hotness Index series for the next 5 days. The prediction performance of the ARIMA model was compared with those of the simple exponential smoothing method (SES) and the Holt linear trend method (Holt). The comparison results are shown in Table 4 and Figure 7.

Table 4. Results of the Incident of "University Banning Food Delivery Service from Campus".

\begin{tabular}{cccccc}
\hline Date & SES & Holt & Value & \multicolumn{2}{c}{ 95\% Confidence Interval } \\
\hline $2018 / 12 / 9$ & 1177.542207 & -4234.533289 & 2385.240369 & -10031.05048 & 14801.53122 \\
$2018 / 12 / 10$ & 1177.542207 & -4339.44855 & 2756.668478 & -10148.14647 & 15661.48343 \\
$2018 / 12 / 11$ & 1177.542207 & -4444.363811 & 2861.88095 & -10081.33355 & 15805.09545 \\
$2018 / 12 / 12$ & 1177.542207 & -4549.279071 & 2891.683929 & -10054.60677 & 15837.97463 \\
$2018 / 12 / 13$ & 1177.542207 & -4654.194332 & 2900.126061 & -10046.41144 & 15846.66356 \\
\hline
\end{tabular}

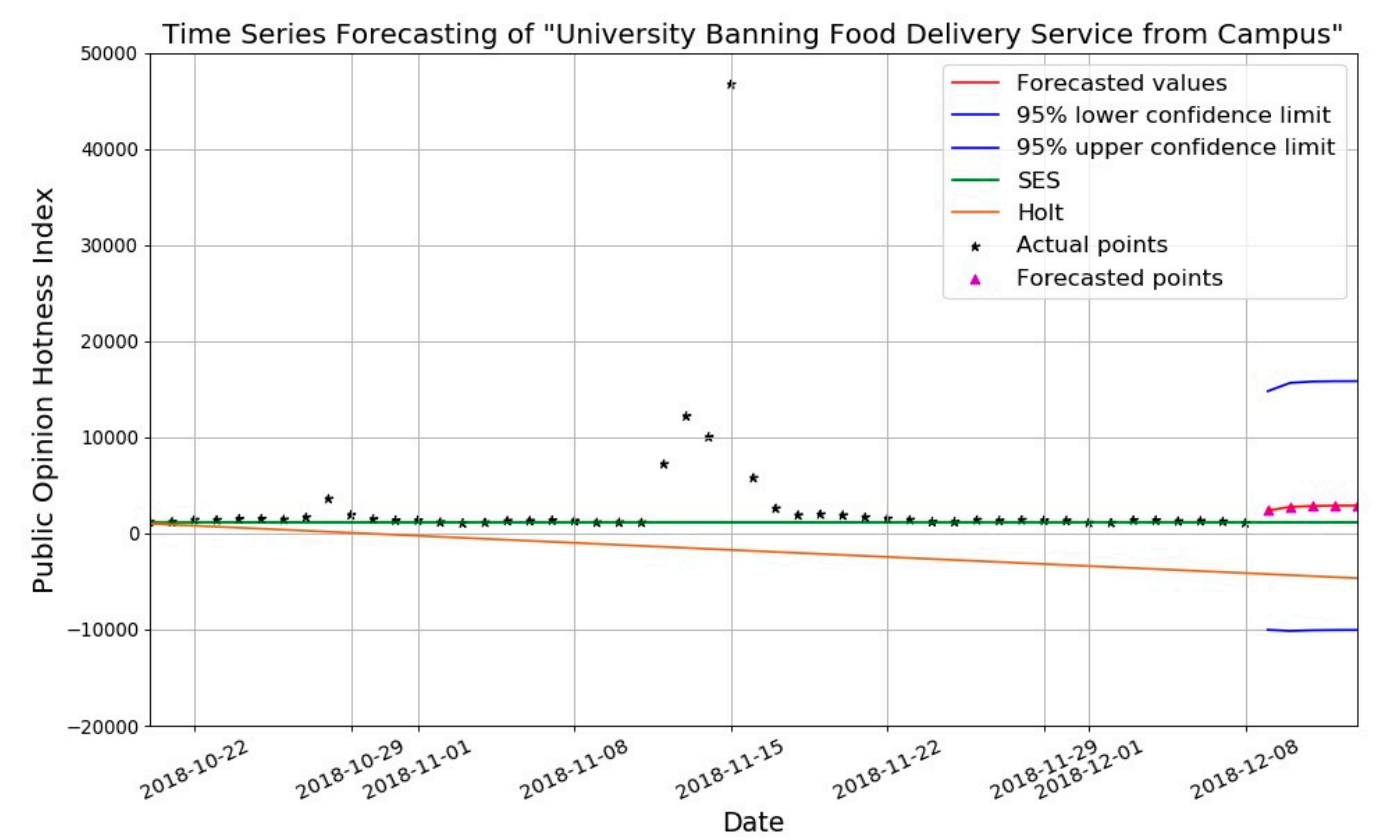

Figure 7. Comparison of the Public Opinion Hotness Index series of the incident of "University Banning Food Delivery Service from Campus".

It can be seen from Table 4 and Figure 7 that the prediction error of the ARIMA model is quite small, and the forecast curve (in red) in the figure falls within $95 \%$ confidence interval. This means that the ARIMA model produces satisfactory trend forecast accuracy on this incident. Moreover, comparing the prediction curves of the other two methods, it can be seen that although the two methods are within the upper $95 \%$ confidence interval, they are unable to effectively predict the variation trend of the sample sequence. The difference between the ground-truth and the predicted values using SES and Holt methods is much larger than that of ARIMA. Based on this comparative analysis, it can be concluded that the ARIMA model outperforms SES and Holt in term of prediction accuracy.

In addition, in order to investigate the stability of the ARIMA model, more datasets of "Sun Yat-sen University Zhangpeng Incident" were analyzed, as shown in Figure 8. The ARIMA model was used to predict the trend of the public opinion index for the last five days. 


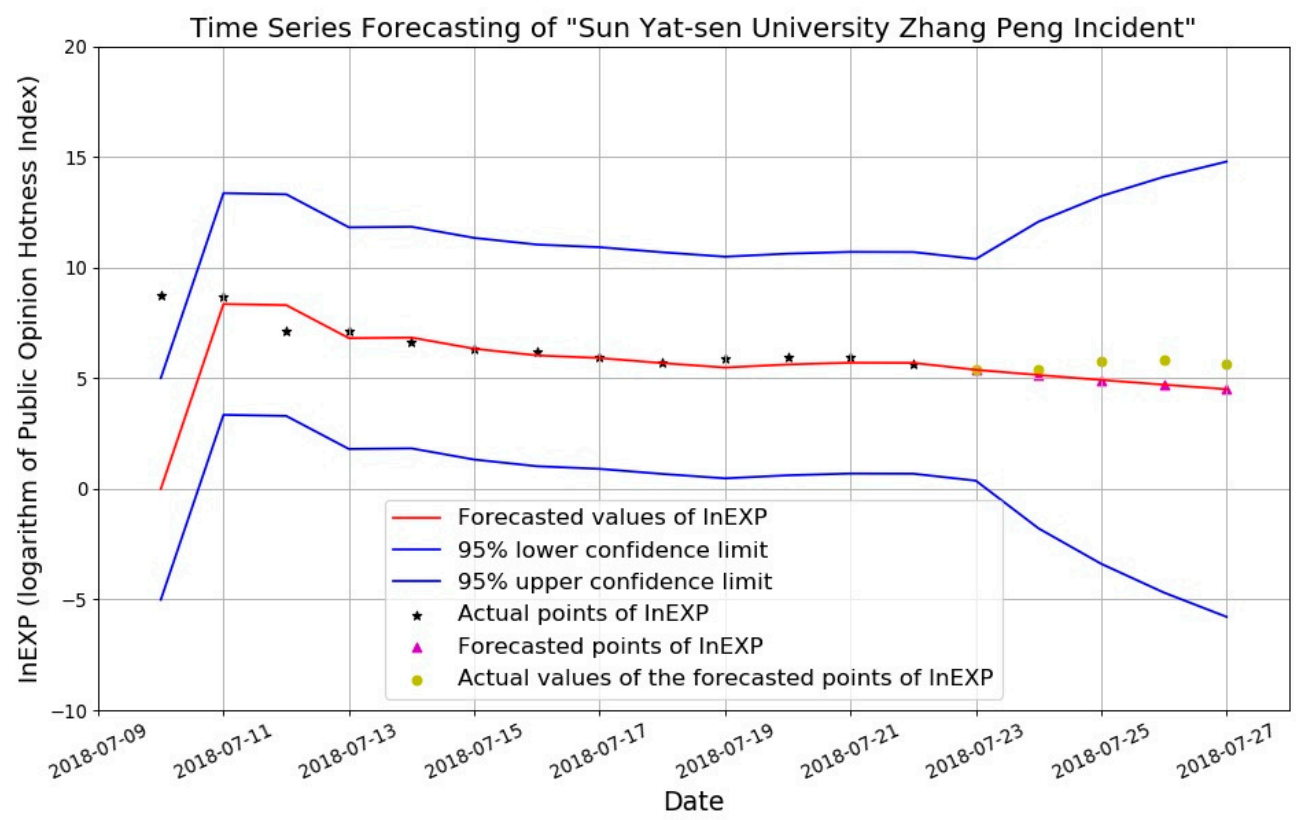

Figure 8. ARIMA prediction result on "Sun Yat-sen University Zhangpeng Incident" datasets.

As can be seen in Figure 8, heat index of "Sun Yat-sen University Zhangpeng Incident" is small, and the difference between the predicted values (red triangle) and the actual value (yellow dot) is small; that is, the model prediction accuracy is satisfactory. Thus, the ARIMA model is applicable to the public opinion events of different universities.

Based on the above analysis, for the public opinion events of colleges and universities, the ARIMA model can be used to predict the development trend in a short-term period.

\subsection{Topic Analysis}

Based on the above-mentioned division of prodromal, outbreak, fluctuating, and fading stages, in the Topic Analysis Module the LDA topic model was used to extract the main topics of netizens at different stages toward the incident of "University Banning Food Delivery Service from Campus". The top 10 keywords were extracted for each topic to reflect the different thoughts triggered by this incident. Then, the word clouds for different stages were generated to visually compare the changes in focuses at different stages. Based on the results of the topic analysis as well as the evolution process analysis, the evolutionary timeline was obtained, as shown in Figure 9.

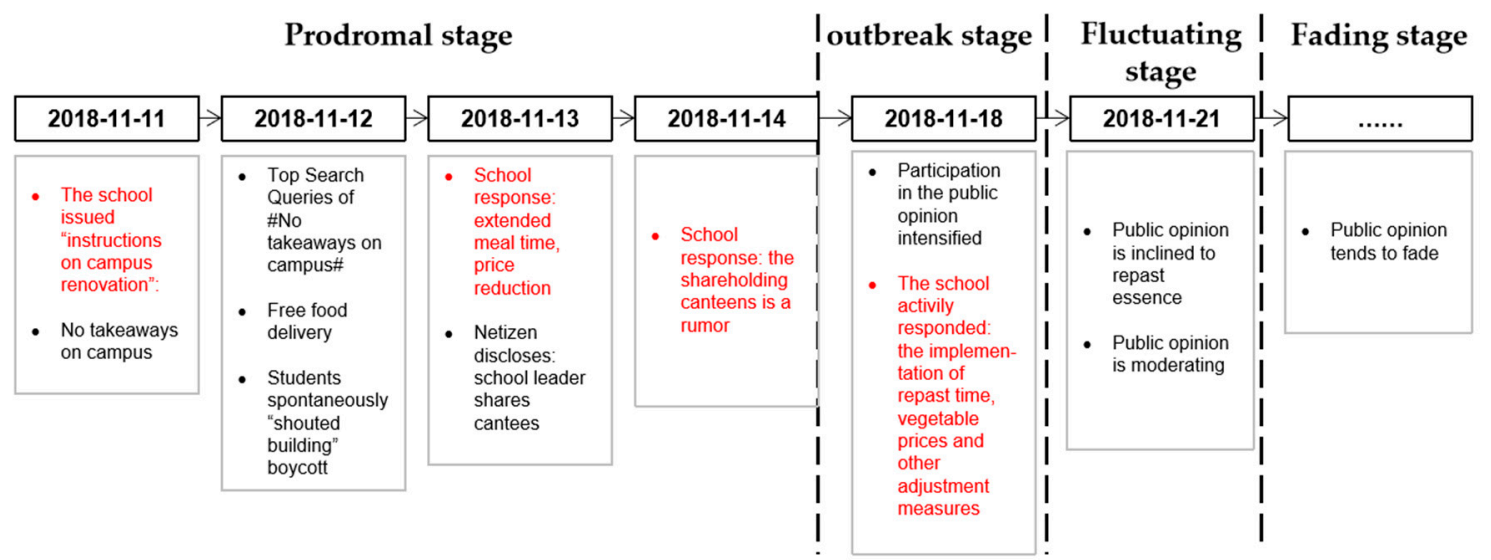

Figure 9. Evolutionary timeline of the incident of "University Banning Food Delivery Service from Campus" and the changes in the topics of public opinions. 
According to Figure 9, “University Banning Food Delivery Service from Campus” became one of the most searched hashtags on 12 November, 2018 after the release of a relevant news story and quickly stirred heated discussions on the Internet. Although the school management did respond in a timely manner, their words were not convincing enough to calm down the public, and the public anger became more severe. After the school management took active measures such as extending the meal time and adjusting the meal prices, the public eventually cooled down on 18 November, 2018. Although debates remained on the Internet, the incident gradually faded out from the public eye on 21 November, 2018. It can be seen that during the evolution of the entire incident, the school management's coping attitudes and measures played a critical role in guiding and mitigating the public opinions.

Furthermore, the LDA topic model was used to extract two topics in each stage, and the top 10 keywords of each topic are shown in Table 5. The word clouds were then created based on these keywords, as shown in Figure 10. It can be seen that with the changes in the behaviors of all involved parties from stage to stage, the topics of public opinions shifted constantly until the incident eventually faded out from the public eye.

Table 5. Topics and keywords at different stages.

\begin{tabular}{cccccccc}
\hline \multicolumn{2}{c}{ Prodromal Stage } & \multicolumn{2}{c}{ Outbreak Stage } & \multicolumn{2}{c}{ Fluctuating Stage } & \multicolumn{2}{c}{ Fading Stage } \\
\hline Topic $\mathbf{1}$ & Topic 2 & Topic $\mathbf{1}$ & Topic 2 & Topic 1 & Topic 2 & Topic 1 & Topic 2 \\
\hline School & Response & Leadership & School & School & Environment & Encourage & Life \\
Campus access & Shareholding & Shareholding & Response & Intention & Canteen & Students & Health \\
Canteen & Leadership & Secretary & Administration & Rights & Hygiene & Health & Reflections \\
Announcement & Corruption & Bidding & Price reduction & Canteen & Quality & Freedom & Modern life \\
Merchants & Management & Interest & Regulation & Response & School & Life & Follow-up \\
Free & Participation & Supervision & Service & Students & Clean & Dormitory & Respect \\
Students & Rumor & Video & Quality & Freedom & Food & Walk out & Food \\
Shouting & Regulation & Word game & Class adjustment & Advocacy & Analysis & Canteen & Students \\
Price reduction & Order & Follow-up & Students & Health & Leadership & Advocacy & Management \\
School gate & Protest & Profit-making & Meal time & Travel & Attention & Access & Continuance \\
\hline
\end{tabular}

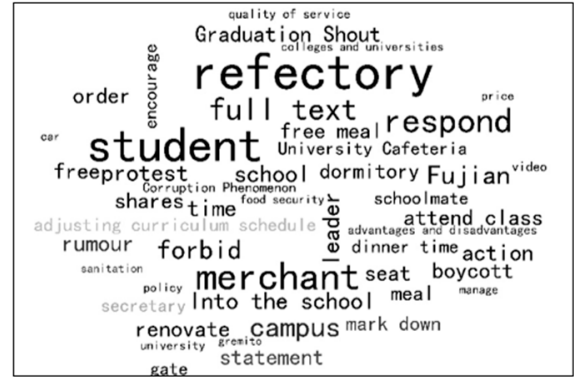

Prodromal Stage

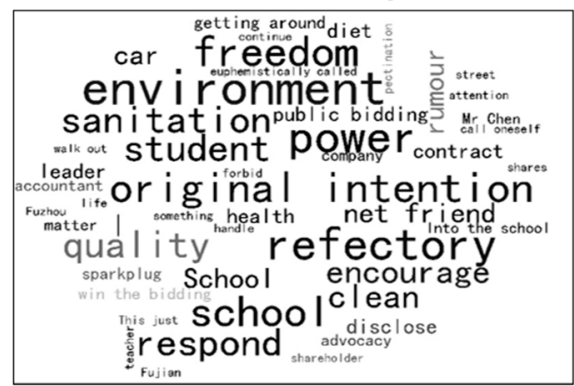

Fluctuating Stage

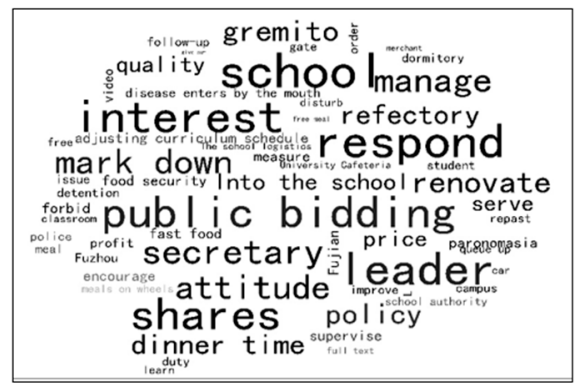

outbreak Stage

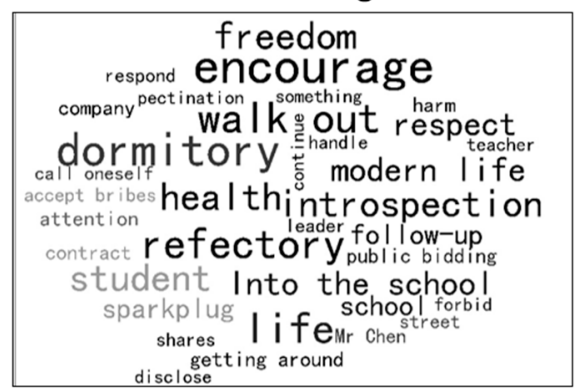

Fading Stage

Figure 10. Word clouds for different stages.

Subsequently, the evolution of the incident based on the topic analysis in different stages was discussed as follows.

(1) Prodromal Stage. The two topics at the prodromal stage mainly focused on two aspects. From high-weight keywords such as "school", "canteen", "announcement", "merchants", "free", "students", 
and "shouting", we can learn that immediately following the breakout of this incident, the public participated in hot discussions on the school's announcement to ban food delivery service from campus, merchants' response, and students' shouting protest. According to the definition of public opinion, "take-away (food)" is a public issue closely related to the vital interests of college teachers and students, and hence is bound to catch public attention. At the same time, from the keyword of "protest", we can see netizens' opposition to the measure of "banning food delivery service from the campus", and it also explains the offline behaviors of young college students.

Later, the school management attempted to quell students' opposition by reducing meal prices. Therefore, the keywords extracted at this stage include "response" and "price reduction". However, keywords such as "shareholding", "leadership", "corruption", and "equity participation" reflect that the public opinions have shifted from initially focusing on self-interest to questioning "official" and "authority". Due to timely response from the school management, the public opinion keywords gradually changed into "response", "rumor", "regulation", "order", etc. In summary, the keywords extracted with this model are in line with the actual offline development of this incident.

In the meantime, although the school management did respond in a timely manner, the topic of discussion still shifted to "corruption", which is of high social sensitivity under the current social environment. Despite this, the school management' response remained formalistic through measures to merely "reduce meal prices and appease the opposition", which failed to address the deep doubts of netizens. Therefore, instead of cooling down the netizens, this incident continued to move forward and build momentum at a faster rate and a larger scale.

(2) Outbreak Stage. At the outbreak stage, the system extracted keywords such as "leadership", "shareholding", "bidding", "interest", reflecting that online discussions still focused on corruption topics such as whether the school management had accepted bribes or became a shareholder of the canteen and whether the school management had carried out public bidding pursuant to the normative procedure. These doubts led to more dissatisfaction and continued to grow, marking the arrival of the outbreak stage.

In order to cope with the online public opinion crisis, the school management actively announced policies to improve campus environment, reduce meal prices, adjust the classes, and improve the service quality, in order to address problems and doubts truly concerned by the public through practical actions. In the meantime, the keywords also changed from the corruption topics to "school", "response", "administration", "price reduction", "regulation", "service", "class adjustment", etc.

From the above analysis, we can see that this incident featured a high hotness level at the outbreak stage, but it can be easily flooded by vicious comments when adverse public opinions gain the upper hand. In case the public opinions are moving forward in an adverse direction, the school management must promptly take the corresponding coping measures to quell public anger and avoid the deterioration of public opinions.

(3) Fluctuating Stage. Keywords such as "school", "original intention", "students", "freedom", "advocacy" and "health" imply that the online discussions have shifted from the corruption topics to more positive one. This is because the school had taken active measures to curb the deterioration of public opinions and shift the focus of discussions back to incident itself, i.e., the original intention of banning food delivery service from campus and the right of students to free choices. Furthermore, there were also a small number of keywords such as "environment", "canteen", "hygiene" and "quality", which highlights students' concern about the hygiene control in school canteens, and also reflects the problems that still exist in the school's logistics management.

(4) Fading Stage. At the fading stage, from keywords such as "encourage", "students", "freedom", "health" and "life", we can see that the netizens had different attitudes towards the way the school management handled this incident, but they were no longer biased towards bribery topics without conclusive evidence. The public opinions tended to become rational. In addition, keywords such as "life", "reflections", "follow-up" and "respect" reflect the follow-up handling and response. These are also the most concerned issues among young college students. 


\section{Sustainability Development}

In Section 4, we demonstrate the analysis process of the network public opinion analysis system in colleges and universities through a case study. Combined with the objective law of the occurrence and development of public opinion, it can be seen that the analysis results have high accuracy. In addition, as shown in Figure 1, college network public opinion is the reflection of the operating state of colleges and universities in terms of image and reputation. Reliable analysis and reasonable response to university network public opinion will contribute to the sustainable operation of the university system. Hence, the authors will present this view in conjunction with the results of the case study.

Firstly, according to Figure 5, we can find the prodromal, outbreak, fluctuating, and fading stages of the "University Banning Food Delivery Service from Campus" event, so there are indeed different development stages for university public opinion events. Secondly, the trend prediction model can effectively predict the heat index of the opinion in the next five days, which can be confirmed from Figures 7 and 8 . The prediction results produced by the proposed ARIMA model are in the $95 \%$ confidence level and have high accuracy. Lastly, the predicted trend data can be used to determine the stage of a public opinion event in a university. For example, in Figure 7 we know the heat index from 22 October to 8 December 2018, including the stages of sharp rise, maximum, and volatility. Based on the stage information, one can judge through the predicted data that the public opinion event has entered the fading stage. Similarly, when predicting other public opinion events, if the generated heat index and the predicted value are both rising, it can be speculated that this public opinion event may still be in the prodromal stage.

However, the division of the development stage of university public opinion events is only the basis for maintaining the sustainable development of the image and reputation of the colleges and universities. Since the lyric theme and the scale of influence of public opinion events will change dynamically, it is more important to analyze, judge and respond to the lyric theme of the public opinion at different stages to get the sustainable development of the image and reputation of the universities.

Specifically, in the prodromal stage, the scale of public opinion is relatively small, which is not enough to endanger the normal operation of the university system. However, the sensational information suggests that problems may arise in university operating systems. If the university management department conducts self-inspection in time in the prodromal stage, finds system loopholes, and optimizes it as soon as possible, it can maintain the normal operation of the university system. According to Figure 10 and Table 5, we can see that in the prodromal stage, the themes of the "University Banning Food Delivery Service from Campus" event mainly reflect people's two opinions: The first one is the protest against the prohibition of takeaway into the campus, and the second one is that the reason for the university to publish regulations is related to corruption. At this point, the management of the university should conduct self-examination based on people's doubts, whether this rule is reasonable, and whether corruption exists. If the regulations are not reasonable or corruption problems do exist, the university management department must solve the problems immediately, otherwise one day these problems will lead to the paralysis of the university operating system. If there are no such problems, colleges and universities should also issue statements in time for their own social reputation and eliminate rumors because negative information may damage the image of colleges and universities in people's minds, and colleges and universities will face a development crisis in the long run if the students are not willing to enter the university for studying.

The influence of network public opinion of colleges and universities in the prodromal stage on the sustainable development of colleges and universities is potential and moderate, but the network public opinion in the outbreak stage brings rapid and dramatic influence on the operation of the university system. In this stage, people's behaviors of expressing opinions go from online to offline; and even form a large-scale behavior that undermines the order of the campus. That is to say, the public opinion incidents that entered the outbreak stage have often caused harm to the normal operation of the university system. At this time, the main goal of the university management department is to minimize the loss as much as possible. For example, in Figure 10 and Table 5, the main question 
of people still remains whether the corruption exists, and people hope that the leaders of school can take measures to solve the problems. Therefore, on one hand, the school should respond to people's doubts and find out whether there exists corruption. On the other hand, the university management department should promote the quality of its service to meet the reasonable demands of students so as to avoid further damage to the operation system of the universities.

In the fluctuating and fading stage, the keywords of network public opinion of colleges and universities will further reflect other problems of the university system, which can help the university management departments to further expand the scope of examination of the university operation system and continuously optimize it. In addition, although the specific content of other universities' online public opinion events is different, the countermeasures are universal. Firstly, the division and trend prediction are used to determine the period, and then, according to the extracted themes, we can confirm which part of the university operation system has problems and solve them. When the various parts of the system operate efficiently and there is no conflict, the university system can achieve good development in a sustainable manner.

\section{Conclusions}

University network public opinion is the feedback to the operation of the university system. University administrators should not only accumulate experience based on positive public opinion information but also optimize the university management system. It should also accurately analyze negative and irrational public opinion information and even rumors. Response in a reasonable way can avoid the collapse of the running system of colleges and universities. To a large certainty, optimizing the system and preventing risks are necessary for the sustainable development of the image and reputation of the colleges and universities. It is especially important to resolve the negative public opinion incidents that may be harmful to the operating system of colleges and universities.

Therefore, this paper proposes a network-based public opinion analysis system based on time series. The system includes: A data acquisition module based on web crawler, a time division module, a trend analysis module based on a time series theory combined with a public opinion index, and an opinion analysis module based on an LDA theme model and a word cloud map. The effectiveness of the system is evaluated by a case study. The analysis results demonstrate that the present method is superior to existing popular models in terms of prediction of short-term trend. Useful sustainable development strategy can be obtained to support the development of the image and reputation of the colleges and universities.

Still, the Public Opinion Hotness Index and public opinion text data-based system for analyzing online public opinions in colleges and universities mainly focus on numerical and text data without taking account of the mining of public opinions contained in images and audio clips. Therefore, future plan will consider the mining and extraction of such types of information.

Author Contributions: W.H. and Y.F. conceived idea; W.H., R.M. and Z.L. performed the data analysis; W.H. and Y.F. wrote the paper; R.M. and Z.L. collected the data and revised the paper.

Funding: This research received no external funding.

Acknowledgments: This research is supported by the Fujian Social Science Planning in 2016 under Grant FJ2016B108 and UOW VC Fellowship.

Conflicts of Interest: The authors declare no conflict of interest.

\section{References}

1. Fan, P.; Wei, S.; Wei, Q. Analysis and Forecasting of Public Opinions in Gansu Province in 2006-2007; Gansu People Press: Lanzhou, China, 2006.

2. Wang, L. Introduction to Lyric Research: Theory, Method and Reality Hotspots; Tianjin Academy of Social Sciences Press: Tianjin, China, 2004; pp. 23-26.

3. Tian, D. Analysis of the value of sustainable development education. Educ. Res. 2013, 8, 25-29. 
4. Ding, Y. The characteristics and work response of university internet public opinion. Chin. High. Educ. 2014, 15, 67-69.

5. Wang, J. Monitoring and guidance of online public opinions in colleges and universities. Netinfo Secur. 2009, 3, 54-57.

6. Wu, Y.; Wang, Y. Construction of the mechanism for managing the public opinions on campus network under uncertainties. Acad. Forum 2009, 7, 186-188.

7. Zhong, Z.; Nie, J. Summary of the research on online public opinions in Chinese colleges and universities. Mod. Educ. Manag. 2011, 5, 68-71.

8. Wang, L. Study on the Mechanism for Analyzing and Guiding Public Opinions in College Students. Master's Thesis, Central South University, Changsha, China, 2010.

9. Du, K. Study on the generating mechanism of online public opinions in colleges and universities and coping strategies. China Youth Study 2011, 7, 102-104.

10. Zheng, S. Some thoughts on the research, judgment and control of online public opinions in colleges and universities. Netw. Secur. Technol. Appl. 2009, 9, 74-77.

11. Wang, X.; Liu, Q. Logic analysis of public opinions on the campus network of colleges and universities. China High. Educ. 2010, 10, 17-19.

12. Chen, $\mathrm{S}$. Research of online public opinion crisis in colleges and universities and coping strategies. China Youth Study 2012, 3, 5-9.

13. Su, L.; Stepchenkova, S.; Kirilenko, A.P. Online public response to a service failure incident: Implications for crisis communications. Tour. Manag. 2019, 73, 1-12. [CrossRef]

14. Kim, S.; Krishna, A.; Plowman, K.D. Winning in the court of public opinion: Exploring public relations-legal collaboration during organizational crisis. Corp. Commun. Int. J. 2019, 24, 96-114. [CrossRef]

15. Baum, M.A.; Potter, P.B.K. Media, public opinion, and foreign policy in the age of social media. J. Politics 2019, 81, 747-756. [CrossRef]

16. Simpson, K. What to do about inequality? Public opinion support for the European Union and further European integration in the Republic of Ireland. Ir. Political Stud. 2019, 34, 69-91. [CrossRef]

17. Laruelle, M. Kazakhstani public opinion of the United States and Russia: Testing variables of (un) favourability. Cent. Asian Surv. 2019, 2109, 1-20. [CrossRef]

18. Franchino, F.; Segatti, P. Public opinion on the Eurozone fiscal union: Evidence from survey experiments in Italy. J. Eur. Public Policy 2019, 26, 126-148. [CrossRef]

19. Huang, X.; Jin, H.; Zhang, Y. Risk assessment of earthquake network public opinion based on global search BP neural network. PLOS ONE 2019, 14, e0212839. [CrossRef]

20. Laughlin, P. Selection strategies in concept attainment as a function of number of persons and stimulus display. J. Exp. Psychol. 1962, 70, 323-327. [CrossRef]

21. Kowalewski, J.; Maxwell, M. Measuring public opinion formation. Agenda Setting J. Theory Pract. Crit. 2019, 3, 43-62. [CrossRef]

22. Park, Y.E.; Son, H.; Yang, S.U.; Lee, J.K. A good company gone bad: An examination of corporate social responsibility agenda-building in times of corporate crisis using machine learning techniques. J. Commun. Manag. 2019, 23, 31-51. [CrossRef]

23. Ip, C.Y.; Liang, C. Effect of violation of social missions on public attitude towards a social enterprise crisis: Mediation of causal attribution and moderation of medium and framing of online articles. Journalism 2019. [CrossRef]

24. Zhu, W.Y. Application of Time Series Analysis; China Renmin University Press: Beijing, China, 2008; p. 146.

25. Blei, D.M.; Ng, A.Y.; Jordan, M.I. Latent dirichlet allocation. J. Mach. Learn. Res. 2003, 3, 993-1022.

26. Marron, A. ‘Overpaid'and 'inefficient': Print media framings of the public sector in The Irish Times and The Irish Independent during the financial crisis. Crit. Discourse Stud. 2019, 16, 282-297. [CrossRef]

(C) 2019 by the authors. Licensee MDPI, Basel, Switzerland. This article is an open access article distributed under the terms and conditions of the Creative Commons Attribution (CC BY) license (http://creativecommons.org/licenses/by/4.0/). 